\title{
NO AD BLOCKERS FOR OLD MEN? DEMOGRAPHIC EVIDENCE FOR AD BLOCKER USAGE FROM GERMANY
}

\author{
Valerio Stallone \\ Zurich University of Applied Sciences, Center for Digital Marketing \\ Stadthausstrasse 14, CH-8400 Winterthur, Switzerland
}

\begin{abstract}
Web users are turning to ad blockers to avoid ads because they perceive them as an invasion of privacy, as annoying or as slackening their internet browsing experience. There has been significant research into factors driving ad blocker adoption. In this paper, the author will highlight significance correlation between ad blocker usage and age. The author conducted an online survey and built two groups, ad blocker users and non-users. When checking for significant differences in the demographic data, the author has found significant difference in the age of ad blocker users.
\end{abstract}

\section{KEYWORDS}

Ad Blocking, Online Advertising, Online Ads, Advertising Avoidance

\section{INTRODUCTION}

Attention is the currency, digital advertising is dealing with (Stourm \& Bax, 2017). In the attempt of getting this crucial resource, different actors play a central role in the digital advertising ecosystem (Stallone \& Klaas, 2019). This ecosystem highlights how digital advertising has become the vital source of revenue for the supply side containing the publishers, who are monetizing their web traffic (Brinson, Eastin, \& Cicchirillo, 2018). To thwart the display of advertisement, numerous companies and organizations have focused on the development of systems (Post \& Sekharan, 2015): In this paper, we will call them ad blockers.

The number of internet consumers adopting ad blocking has grown worldwide over the past five years and as the internet consumers become increasingly conscious of the possibility of ad blocking, even higher adoption rates must be expected globally (Tudoran, 2019).

This research contributes to the literature on online consumer behavior by highlighting demographic evidence of ad blocker usage. The author do so by analyzing a dataset from a German online survey and showing how the self-reported age correlates with the self-reported usage of ad blockers on desktop devices.

\section{LITERATURE REVIEW}

This review investigates the literature on ad blockers. The author selected peer-reviewed articles from four bibliographic databases (IEEE Xplore, Sage journals online, Science Direct \& Google Scholar). The author considered peer-reviewed journals and conference proceedings based no their knowledge validity and their highest impact on the research field. To ensure the relevance of the articles in this study, the author used a combination of four keywords, contained at least in the abstract of the selected articles. The search of articles was limited to English \& German speaking journals between $2007 \&$ 2019. The rationale is to capture the latest change in investigating ad blockers.
1. *ad blocker*
2. *adblocker*
3. *ad blocking*
4. *adblocking* 


\subsection{Ad Blocker}

In the legal field, academic literature tries to understand the implications of using ad blocker from the perspective of a whole country and/or from the publisher as an affected actor of the digital advertising ecosystem (Abrahamsen, 2017; Barbacovi, 2016; Lu, 2017; R. Miller, 2017; R. A. Miller, 2018).

Economic analyses show models on how the usage of ad blockers is affecting the players involved (Aseri, Dawande, Janakiraman, \& Mookerjee, 2018; Bounie, Vallrie, \& Quinn, 2017; Despotakis, Ravi, \& Srinivasan, 2017; Jain, Czerwinski, Song, \& He, 2010; Miklosik, Kuchta, \& Zak, 2018; Ray, Ghasemkhani, \& Kannan, 2017; Streitz \& Tynan, 2016) with game theoretical approaches.

Scholars in the technological field research on how to develop either new ad blocking or anti ad blocking solutions (Backes, Bugiel, Styp-Rekowsky, \& WiBfeld, 2017; Ikram \& Kaafar, 2017a, 2017b; Jalba, Olteanu, \& Draghici, 2016; Lashkari, Seo, Gil, \& Ghorbani, 2017; Mughees, Qian, \& Shafiq, 2017; Mughees, Qian, Shafiq, Dash, \& Hui, 2016; Nithyanand et al., 2016; Tramèr, Dupré, Rusak, Pellegrino, \& Boneh, 2018; Wills \& Uzunoglu, 2016).

Researches in the behavioral field contains researches into the identification of factors influencing the usage of ad blockers. The most important factors leading the use of ad blocker are the needs for security/privacy, for avoiding further interruption online and for page loading speed (Boerman, Kruikemeier, \& Zuiderveen Borgesius, 2018; Brinson et al., 2018; Mccoy, Everard, Polak, \& Galletta, 2007; Redondo \& Aznar, 2018; Zhao et al., 2017).

\subsection{Age and Ad Blocker Usage}

Young reported in his study, that "older individuals tended to report using ad blockers less [than younger individuals]" (Young, 2016). In another research it has been stated that there are no significant differences younger and older adults with respect to privacy concerns and privacy protective behaviors (Boerman et al., 2018)- both motivational factors for the usage of ad blockers as stated before. A significant difference was shown by Zhao et al., which stated that "people who are younger than 34 are more likely to use ad blockers" (Zhao et al., 2017). eMarketer states in its study of 2017 that "ad blocking continues to be far more prevalent among younger people" (eMarketer, 2017). Within their study, Despotakis et al. implied, by citing the PageFair and Adobe report that older non-ad blocker users would never use an ad blocker (Despotakis et al., 2017; PageFair \& Adobe, 2015). Only the data of PageFair \& Adobe could represent the reality, since every other research represented self-reported data on the usage of ad blocker.

\section{RESEARCH METHOD}

\subsection{Data Collection}

AdDefend designed a questionnaire, Appinio distributed the final questionnaire online to the Appinio panel members and managed the collection, monitoring, and processing of the data. AdDefend is an independent platform for ad block advertising that displays ads to users of ad blockers. That way, publishers remonetize their content with ads, advertisers have the opportunity to address this target group and users keep free access to their favorite content. Appinio is a German market research company.

Data for the study was collected with an online questionnaire targeted for Internet users from Germany. The survey resulted in 1511 valid responses. The questionnaire contained 22 questions about their internet consumption on desktop devices. The survey has been conducted during the second half of December 2018 to be sure to have a high density of ads shown to the participants due to the Christmas-related advertisement.

\subsection{Participants}

1761 panelists completed the questionnaire. 250 subjects were invalidated for having inconsistently and/or incompletely responded to the questions. 


\section{RESULTS}

\subsection{Descriptive Results}

The final sample consisted of 1511 subjects ( $56 \%$ males and $44 \%$ females), with the following age distribution: $13 \%$ under 18 years of age, 34\% aged between 18 and 24, 28\% aged between 25 and 34, 15\% aged between 35 and 44 and $9 \%$ above 45 . Almost $48 \%$ of respondents reported to consume internet content multiple hours a day, $16 \%$ one hour a day, $16 \%$ multiple hours per week and almost $20 \%$ less than the above. Regarding ad blocker usage, $50 \%$ of the subjects were current users and $50 \%$ of the subjects were not current users.

\subsection{Differences in Age}

The author conducted first a t-test to explore any significant difference in age between the two groups of respondents. The author detected a significant result, which is shown in Table 1.

Table 1. Ad Blocker Use t-test

\begin{tabular}{lcccc}
\hline & \multicolumn{3}{c}{ Ad Blocker Use } \\
\hline & \multicolumn{3}{c}{ Yes } & \multicolumn{3}{c}{ No } \\
\hline & Mean & SD & Mean & SD \\
Age & 26.97 & 9.371 & 28.29 & 11.797 \\
\hline
\end{tabular}

Ad blocker users are significantly younger $(\mathrm{p}<0.05)$, which is also stated in Table 2 with a correlation value of 0.062 .

Table 2. Ad Blocker and age correlation

\begin{tabular}{lccc}
\hline & & Variables & \\
\hline Ad Blocker Use & & Ad Blocker Use & Age \\
& $\begin{array}{c}\text { Correlation } \\
\text { Significance } \\
\text { (two-sided) } \\
\text { Age }\end{array}$ & 1 & $-0.062 *$ \\
& $\begin{array}{c}\mathrm{N} \\
\text { Correlation } \\
\text { Significance } \\
\text { (two-sided) } \\
\text { N }\end{array}$ & 1511 & 1511 \\
& & $-0.062 *$ & 1 \\
& & 1511 & 1511
\end{tabular}

These results do not differ from the ones presented by (Young, 2016). The following article shows a lower significance $(\mathrm{p}<0.05$ versus $\mathrm{p}<.01)$ as well as a lower $\beta(-0.012$ versus -0.093$)$ than the mentioned one, which the Young identified running a simple binary regression explaining the fact of using an ad blocker by the age of the user (Young, 2016). The main difference though lies in the methodology: Whilst AdDefend surveyed exclusively about ad blocker usage, Young used data of YouGov for an annual report that "looks to map the changing ecology of news across countries" (Young, 2016). Another difference is, of course, the time stamp of the survey: YouGov's survey was taken in January 2015, AdDefend distributed it in December 2018 - almost four years. 


\section{DISCUSSION}

\subsection{Conclusion}

This very first analysis of ad blocker use in Germany showed that there is almost no difference to other studies done in the United Kingdom and the United States. In this paper, the author highlighted the lack of thorough analysis of the influence of age on the usage of ad blockers. It confirms what has been found up until now in literature but shows a slight less intense correlation between the two variables, which can be due to cultural but also to simple sample differences.

\subsection{Further Research}

In this paper, the author showed the need for a thorough focus on the effects of age on ad blocker usage. To be able to identify the differences between younger and older users better, scholars should investigate the differences in motivational factors of ad blocker usage between the two groups: Are there the same significant differences within the sub-group of millennials and silver surfers? Besides the differences in age, the author suggests to move on with more analyses from other countries: Are there any differences from a cultural perspective? Ad blocker demographics should therefore remain a crucial focus in this field of academia.

\section{REFERENCES}

Abrahamsen, J. T. (2017). Ad Blockers, Convenience or Trespass: Click Here to Find out. University of Illinois Journal of Law, Technology \& Policy, $2017 . \quad$ Retrieved from https://heinonline.org/HOL/Page?handle=hein.journals/jltp2017\&id=499\&div=\&collection=

Aseri, M., Dawande, M., Janakiraman, G., \& Mookerjee, V. (2018). Ad-Blockers: A Blessing or a Curse? SSRN Electronic Journal. https://doi.org/10.2139/ssrn.3299057

Backes, M., Bugiel, S., Styp-Rekowsky, P. von, \& WiBfeld, M. (2017). Seamless In-App Ad Blocking on Stock Android. In 2017 IEEE Security and Privacy Workshops (SPW) (pp. 163-168). IEEE. https://doi.org/10.1109/SPW.2017.24

Barbacovi, T. (2016). Blocking Ad Blockers. John Marshall Review of Intellectual Property Law, 16. Retrieved from https://heinonline.org/HOL/Page?handle=hein.journals/johnmars16\&id=283\&div=\&collection=

Boerman, S. C., Kruikemeier, S., \& Zuiderveen Borgesius, F. J. (2018). Exploring Motivations for Online Privacy Protection Behavior: Insights From Panel Data. Communication Research, 9365021880091. https://doi.org/10.1177/0093650218800915

Bounie, D., Vallrie, M., \& Quinn, M. (2017). Do You See What I See? Ad Viewability and the Economics of Online Advertising. SSRN Electronic Journal. https://doi.org/10.2139/ssrn.2854265

Brinson, N. H., Eastin, M. S., \& Cicchirillo, V. J. (2018). Reactance to Personalization: Understanding the Drivers Behind the Growth of Ad Blocking. Journal of Interactive Advertising, 18(2), 136-147. https://doi.org/10.1080/15252019.2018.1491350

Despotakis, S., Ravi, R., \& Srinivasan, K. (2017). The Beneficial Effects of Ad Blockers. SSRN Electronic Journal. https://doi.org/10.2139/ssrn.3083119

eMarketer. (2017). eMarketer Scales Back Estimates of Ad Blocking in the US - eMarketer. Retrieved June 21, 2019, from https://www.emarketer.com/Article/eMarketer-Scales-Back-Estimates-of-Ad-Blocking-US/1015243

Ikram, M., \& Kaafar, M. A. (2017a). A First Look at Ad Blocking Apps on Google Play. Retrieved from http://arxiv.org/abs/1709.02901

Ikram, M., \& Kaafar, M. A. (2017b). A first look at mobile Ad-Blocking apps. In 2017 IEEE 16th International Symposium on Network Computing and Applications (NCA) (pp. 1-8). IEEE. https://doi.org/10.1109/NCA.2017.8171376

Jain, K., Czerwinski, M., Song, Y., \& He, L.-W. (2010). Evaluating the Unaccounted Cost of Distraction of Display Ads to the Users. Retrieved from http://seattletimes.nwsource.com $/ \mathrm{html} / \mathrm{businesstechnology/}$

Jalba, I., Olteanu, A.-C., \& Draghici, A. (2016). Customized ad blocking. In 2016 15th RoEduNet Conference: Networking in Education and Research (pp. 1-5). IEEE. https://doi.org/10.1109/RoEduNet.2016.7753245

Lashkari, A. H., Seo, A., Gil, G. D., \& Ghorbani, A. (2017). CIC-AB: Online ad blocker for browsers. In 2017 International Carnahan Conference on Security Technology (ICCST) (pp. 1-7). IEEE. https://doi.org/10.1109/CCST.2017.8167846 
$\mathrm{Lu}, \mathrm{B}$. (2017). The unique Chinese legal approach to online ad blocking: Is it in the right direction? Computer Law \& Security Review, 33(6), 786-801. https://doi.org/10.1016/J.CLSR.2017.05.012

Mccoy, S., Everard, A., Polak, P., \& Galletta, D. F. (2007). THE EFFECTS OF ONLINE ADVERTISING. COMMUNICATIONS OF THE ACM (Vol. 50 ). Retrieved from http://delivery.acm.org/10.1145/1230000/1226740/p84-mccoy.pdf?ip=160.85.7.55\&id=1226740\&acc=ACTIVE SERVICE\&key=FC66C24E42F07228.89BA465B3F8E8007.4D4702B0C3E38B35.4D4702B0C3E38B35\&_acm_ =1559306947_6eb4260fd60ab7f3e89ab5051f91906c

Miklosik, A., Kuchta, M., \& Zak, S. (2018). Privacy Protection Versus Advertising Revenues: The Case of Content Publishers. Connectist: Istanbul University Journal of Communication Sciences, 54, 117-140. https://doi.org/10.26650/CONNECTIST404711

Miller, R. (2017). Liberation, Not Extortion: The Fate of Internet Ad-Blocking in German and American Law. SSRN Electronic Journal. https://doi.org/10.2139/ssrn.3019254

Miller, R. A. (2018). The Legal Fate of Internet Ad-Blocking. Boston University Journal of Science and Technology Law, 24. Retrieved from https://heinonline.org/HOL/Page?handle=hein.journals/jstl24\&id=317\&div=\&collection=

Mughees, M. H., Qian, Z., \& Shafiq, Z. (2017). Detecting Anti Ad-blockers in the Wild. Proceedings on Privacy Enhancing Technologies, 3, 130-146. https://doi.org/10.1515/popets-2017-0032

Mughees, M. H., Qian, Z., Shafiq, Z., Dash, K., \& Hui, P. (2016). A First Look at Ad-block Detection: A New Arms Race on the Web. https://doi.org/10.1145/1235

Nithyanand, R., Khattak, S., Javed, M., Vallina-Rodriguez, N., Falahrastegar, M., Powles, J. E., ... Murdoch, S. J. (2016). Adblocking and Counter Blocking: A Slice of the Arms Race. In 6th USENIX Workshop on Free and Open Communications on the Internet (FOCI 2016). Retrieved from https://www.usenix.org/conference/foci16/workshopprogram/presentation/nithyanand

PageFair, \& Adobe. (2015). The Cost of Ad Blocking: PageFair and Adobe 2015 Ad Blocking Report. PageFair and Adobe Ad Blocking Report. Retrieved from http://downloads.pagefair.com/reports/2015_report-the_cost_of_ad_blocking.pdf

Post, E. L., \& Sekharan, C. N. (2015). Comparative Study and Evaluation of Online Ad-Blockers. In 2015 2nd International Conference on Information Science and Security (ICISS) (pp. 1-4). IEEE. https://doi.org/10.1109/ICISSEC.2015.7370988

Ray, A., Ghasemkhani, H., \& Kannan, K. N. (2017). Ad-Blockers: Extortionists or Digital Age Robin Hoods? SSRN Electronic Journal. https://doi.org/10.2139/ssrn.2991805

Redondo, I., \& Aznar, G. (2018). To use or not to use ad blockers? The roles of knowledge of ad blockers and attitude toward online advertising. Telematics and Informatics, 35(6), 1607-1616. https://doi.org/10.1016/J.TELE.2018.04.008

Stallone, V., \& Klaas, M. (2019). The Digital Advertising Ecosystem Visualization - Literature Review. Retrieved from http://www.iadisportal.org/digital-library/the-digital-advertising-ecosystem-visualization-- -literature-review

Stourm, V., \& Bax, E. (2017). Incorporating hidden costs of annoying ads in display auctions. International Journal of Research in Marketing, 34(3), 622-640. https://doi.org/10.1016/J.IJRESMAR.2017.02.002

Streitz, M., \& Tynan, R. (2016). Are ad-blockers killing the media? Speigel Online's Matthias Streitz in a head-to-head debate with Privacy International's Richard Tynan. Index on Censorship, 45(2), 78-80. https://doi.org/10.1177/0306422016657033

Tramèr, F., Dupré, P., Rusak, G., Pellegrino, G., \& Boneh, D. (2018). Ad-versarial: Perceptual Ad-Blocking meets Adversarial Machine Learning. Retrieved from http://arxiv.org/abs/1811.03194

Tudoran, A. A. (2019). Why do internet consumers block ads? New evidence from consumer opinion mining and sentiment analysis. Internet Research, 29(1), 144-166. https://doi.org/10.1108/IntR-06-2017-0221

Wills, C. E., \& Uzunoglu, D. C. (2016). What Ad Blockers Are (and Are Not) Doing. In 2016 Fourth IEEE Workshop on Hot Topics in Web Systems and Technologies (HotWeb) (pp. 72-77). IEEE. https://doi.org/10.1109/HotWeb.2016.21

Young, J. (2016). MEET THE BLOCKERS: A QUANTITATIVE ANALYSIS OF AD BLOCKER USAGE. Middle Tennessee State University. $\quad$ Retrieved from https://jewlscholar.mtsu.edu/bitstream/handle/mtsu/5033/Young_mtsu_0170N_10656.pdf?sequence=1\&isAllowed=y

Zhao, S., Wang, C., Kalra, A., Vaks, L., Borcea, C., \& Chen, Y. (2017). Ad Blocking and Counter-Ad Blocking: Analysis of Online Ad Blocker Usage. AMCIS 2017 Proceedings. Retrieved from https://aisel.aisnet.org/amcis2017/DataScience/Presentations/29 